\title{
Cooperative policing behavior regulates reproductive division of labor in a termite
}

\author{
Qian Sun ${ }^{1,2}$, Jordan D. Hampton ${ }^{2}$, Kenneth F. Haynes $^{2}$, Austin Merchant ${ }^{2}$, Xuguo Zhou ${ }^{2 *}$
}

1. Department of Entomology, Louisiana State University Agricultural Center, Baton Rouge, LA

70803, USA

2. Department of Entomology, University of Kentucky, Lexington, KY 40546-0091, USA

\section{Q.S. and J.D.H. contributed equally to this work.}

\section{*Corresponding Author:}

Dr. Xuguo "Joe" Zhou

Department of Entomology

University of Kentucky

S-225 Agricultural Science Center North

Lexington, KY 40546-0091

Phone: 859-257-3125; Fax: 859-323-1120

Email: xuguozhou@uky.edu

Short Title: Policing behavior in termites 


\section{Abstract}

2 Reproductive conflicts are common in insect societies where helping castes retain reproductive

3 potential. One of the mechanisms regulating the conflicts is policing, a coercive behavior that

4 reduces direct reproduction by other individuals. In eusocial Hymenoptera (ants, bees, and

5 wasps), workers or the queen act aggressively toward fertile workers, or destroy their eggs. In

6 many termite species (order Blattodea), upon the death of primary queen and king, workers or

7 nymphs can differentiate into neotenic reproductives and inherit the breeding position. During

8 this process, competition among neotenics is inevitable, but how this conflict is resolved remains

9 unclear. Here, we report a policing behavior that regulates reproductive division of labor in the

10 eastern subterranean termite, Reticulitermes flavipes. Our results demonstrate that the policing

11 behavior is a cooperative effort performed sequentially by successful neotenics and workers. A

12 neotenic reproductive initiates the attack of the fellow neotenic by biting and displays alarm

13 behavior. Workers are then recruited to cannibalize the injured neotenic. Furthermore, the

14 initiation of policing is age-dependent, with older reproductives attacking younger ones, thereby

15 inheriting the reproductive position. This study provides empirical evidence of policing behavior

16 in termites, which represents a convergent trait shared between eusocial Hymenoptera and

17 Blattodea.

18

19 Keywords: policing behavior, reproductive conflict, neotenic reproduction, termites, eusociality 


\section{Introduction}

21 Eusocial insects exhibit reproductive division of labor between a few reproductive individuals

22 and numerous sterile workers. However, potential conflicts arise in species where workers are

23 capable of reproduction [1-4]. In addition to queen pheromones that suppress worker

24 reproduction in many species [5-7], policing behavior is an important solution to maintain

25 reproductive harmony [2, 8]. Queen policing, a term coined by Oster and Wilson in 1978,

26 describes behaviors carried out by the queen to retain her reproductive dominance over workers

27 [9]. Worker policing, which was named by Ratnieks in 1988, was used to describe the actions of

28 workers that reduce worker-produced males in favor of sons of the queen in honey bee [8]. The

29 concept of "policing behavior" was expanded by Monnin and Ratnieks in 2001 to include all

30 "coercive actions that reduce direct reproduction by other individuals", which accommodates

31 various forms of behavioral regulation observed in diverse social insects [10]. In eusocial

32 Hymenoptera (ants, bees, and wasps), policing behavior is performed via egg-eating or different

33 forms of aggression, such as immobilization, biting, and stinging [10-13]. Policing interactions

34 may occur among workers [11], among reproductives [14, 15], or between reproductives and

35 workers [12, 16-18]. However, the vast majority of investigations on policing behavior have

36 been focused on Hymenoptera, with little is known about its occurrence or nature in termites

37 (order Blattodea), a group of eusocial insects evolved 50 million years earlier than eusocial

38 Hymenoptera [19].

39 Policing behavior serves two functions that are not mutually exclusive, which are

40 regulating genetic conflicts and improving colony efficiency [8, 20, 21]. Genetic conflicts arise

41 between colony members due to relatedness asymmetries. For example, in social Hymenoptera

42 with haplodiploid sex determination, workers are often capable of laying unfertilized male eggs, 
43 and they are more closely related to their own sons than males produced by other individuals [2,

$448,22]$. Moreover, policing behavior contributes to colony efficiency even when little or no

45 genetic conflict is present, as it optimizes the allocation of colony resources to reproduction [8,

46 23], or maintains an adaptive colony-level phenotype [24].

47 Unlike social Hymenoptera, termite colonies are usually founded and dominated by a pair

48 of primary reproductives (queen and king). Upon their death, neotenic reproductives of both

49 sexes can differentiate either from workers, which become ergatoid reproductives, or from

50 nymphs, which become nymphoid reproductives [25]. Reproductive succession by neotenics has

51 been reported in at least $13.4 \%$ of "higher" termite genera (Termitidae) and $61.7 \%$ of "lower"

52 termite genera (all other termite families) [26]. In termites with diplodiploid sex-determination,

53 individuals are more closely related to their own offspring than that of their siblings, regardless

54 of outbreeding or inbreeding. Therefore, genetic conflicts are potential and competition for

55 reproduction between nestmates is expected [27]. Moreover, given the fact that workers are

56 reproductively totipotent in many species, colony-level efficiency can be compromised if excess

57 neotenics differentiate, as it results in reduced labor force and increased resource demand by the

58 reproductives and their brood.

59 In the presence of fertile reproductives, neotenic formation is inhibited through

60 pheromones [6, 28, 29], and policing behavior through overt aggression was considered rare in

61 termites $[28,30]$. However, during the process of reproductive succession when colonies are

62 orphaned and inhibitory pheromones are temporarily absent, production of excessive neotenic

63 reproductives in the colony is expected. In addition, cannibalism of neotenics was observed in

64 several termite families including Termopsidae [31], Kalotermitidae [30, 32-34] and

65 Rhinotermitidae [35, 36], suggesting the presence of policing behavior that directly regulates 
66 reproduction in termites. Empirical studies of the process and causes of policing behavior,

67 however, are lacking. In this study, we conducted a series of experiments to understand whether

68 the number of ergatoid neotenics is regulated behaviorally during reproductive succession, and

69 how policing behavior is performed in the eastern subterranean termite, Reticulitermes flavipes.

70 Furthermore, we investigated a proximate factor that determines the succession of reproductives.

2. Methods

\section{3 (a) Insect collection and maintenance}

74 Field and laboratory colonies of $R$. flavipes were used in this study. Field colonies were collected

75 from Red River Gorge area, Daniel Boone National Forest (Slade, Kentucky, USA) and the

76 University of Kentucky Arboretum (Lexington, Kentucky, USA). These colonies were obtained

77 in summer using trapping stations filled with dampened cardboard rolls. Once captured termites

78 were extracted from traps, placed in Petri dishes $(14.5 \mathrm{~cm} \times 2.0 \mathrm{~cm})$ with moistened unbleached

79 paper towel as their only food source for 7- 10 days before they were used in experiments. Only

80 workers and soldiers were collected from the field. Laboratory colonies were established in 2010

81 by pairs of sibling alates from a dispersal flight in Lexington, Kentucky, and they were kept in

82 closed plastic boxes filled with moistened wood mulch and pinewood blocks in laboratory for 5

83 years before use. All colonies were maintained in complete darkness ( $\mathrm{L}: \mathrm{D}=0: 24)$, at $27 \pm 1^{\circ} \mathrm{C}$,

$8480 \%-99 \%$ RH.

\section{5 (b) Orphaning assay to test ergatoid number restriction}

86 This assay was used to simulate the reproductive replacement process after the death of primary

87 reproductives. Groups of 100 workers were kept in petri dishes (35-mm-diameter) with

88 moistened paper towel placed at the bottom. Two treatments including "removal" and "non- 
removal" of ergatoids were conducted. This experiment was specifically designed in a way to

90 compare between the numbers of ergatoids that can potentially differentiate and survive

91 ("removal") and that actually survived ("non-removal"). All termites were maintained at $27 \pm$

$92 \quad 1^{\circ} \mathrm{C}$ and in complete darkness for 90 days. Each dish was checked by identifying the sex and

93 counting the number of newly differentiated ergatoids. Each ergatoid was removed and replaced

94 with a worker in the "removal" treatment, but returned to the dishes in the "non-removal"

95 treatment. Dishes in "removal" treatment were checked every day, while dishes in "non-

96 removal" treatment were checked every 10 days to reduce stress to reproductives resulting from

97 manipulations needed for sex identification. The number of remaining termites in each group

98 was counted every 30 days, and mortality was calculated based on the difference between the

99 numbers of initial and remaining individuals. Injured ergatoids were not counted. A total of 20

100 replications were made with five replications in each of the four colonies. Two field and two

101 laboratory colonies were used in this experiment.

\section{2 (c) Orphaning assay for observation of policing behavior}

103 This assay was designed to observe policing behavior under orphaning condition, which

104 resembled the "non-removal" treatment above. The dishes were incubated at $27 \pm 1^{\circ} \mathrm{C}$ for a total

105 of 90 days. Once a week, the dishes were checked for dryness, and water was added if the paper

106 towels at the bottom appeared to be dry. Between 60 and 90 days, each dish was checked for the

107 presence of ergatoids, and the dishes with ergatoids were selected to be video recorded for 6 days.

108 Video cameras (Canon Vixia HF G20, Canon Inc., Tokyo, Japan) were used for recording and

109 yield high quality images. The dishes and the cameras were shaded under a piece of cardboard

$110(1.5 \mathrm{~m} \times 0.8 \mathrm{~m})$ during recording. Ergatoids were identified as males or females and color

111 marked using enamel paint (Testor Corporation, Rockford, IL, USA) on their head capsule prior 
112 to recording. During recording, the dishes were checked every day for missing ergatoids (which

113 were cannibalized), and newly formed ergatoids were color marked. When a marked ergatoid

114 was missing, the video of the previous 24 hours was quantitatively analyzed.

115 We define the "victim" as the ergatoid that was eventually cannibalized, the "attacker" as

116 the individual who attacked the victim, and "bystander" as the ergatoids who did not perform the

117 first major attack. A major attack was recognized when the attacker visibly injured the victim

118 such that the researcher could see the abdomen was torn, hemolymph was leaking, and the victim

119 quickly fled. The first major attack was designated as time " 0 ", and the frequency of vibration

120 and number of workers surrounding the victim were documented. A one-minute sample (30

121 seconds before and after the time point) was analyzed for all these behaviors, with the sample

122 selected for the time midpoints $5,15,20,25,30,45$, and 60 minutes before and after time " 0 ".

123 Worker density near the victim was an indicator of cannibalism. The density was quantified by

124 counting the number of workers and soldiers within $4 \mathrm{~mm}$ radius from the center of the victim

125 (the radius approximately equals to body length of a worker). Only field-collected colonies were

126 used in this experiment.

\section{7 (d) Policing assay to test the effect of ergatoid age}

128 This assay was used to determine if policing behavior in $R$. flavipes is associated with the age of

129 ergatoids. Each group of 50 workers was kept in a petri dish (55-mm-diameter) lined with 6

130 layers of moistened paper towel. A pair of virgin ergatoids, female and male, was added to each

131 dish on day 1. Female and male treatments were conducted, with a younger female or male

132 ergatoid being added to the initial group every day. When added to the dish, the initial pair of

133 ergatoids was 7 days post differentiation (7-day old) and became older over the course of the

134 experiment, and subsequent ergatoids were no more than 7-day old. All of the ergatoids were 
135 color marked as previously described, and no new ergatoids differentiated during this assay. The

136 dishes were recorded until one of the ergatoids was missing. The video was then analyzed to

137 identify who attacked that ergatoid. A total of 9 and 10 replications were made for female and

138 male treatments, respectively; aggressively interacting pairs that were the same sex were

139 analyzed for their age differences. This experiment did not attempt to address sex-specificity, but

140 it was designed for increased chance of sex-specific aggression, and only same-sex aggressions

141 were analyzed to eliminate confounding factors associated with sex. Only field-collected

142 colonies were used in this experiment.

\section{3 (e) Statistical analyses}

144 Data were analyzed using R (https://www.r-project.org/) and Statistix 10 (Analytical Software,

145 Tallahassee, FL, USA), and graphs were generated using SigmaPlot 13 (Systat Software Inc,

146 Chicago, IL, USA). Data for ergatoid number and mortality in reproductive "removal" and "non-

147 removal" assays were fitted to Poisson family generalized linear mixed models using R's glmer

148 function. In the model for ergatoid number, ergatoid sex and treatment group (removal vs. non-

149 removal) were coded as fixed effects, while colony of origin was coded as a random effect. An

150 observation-level random effect was introduced to avoid overdispersion. In the model for

151 mortality, treatment group was coded as a fixed effect, while colony of origin was coded as a

152 random effect. In both cases, data were analyzed separately for each 10-day interval. Data testing

153 the influence of ergatoid age on aggressive interactions in the policing assay were analyzed in

154 Statistix using a Wilcoxon signed-rank test.

155

156 3. Results

157 (a) The number of ergatoids is restricted 
158 In "removal" treatment, there were significantly more female and male ergatoids differentiated

159 than that remained in "non-removal" treatment within 90 days (Figure $1 ; \mathrm{x}^{2}=137.14, \mathrm{df}=1, P<$

160 0.001; GLMM, Poisson family; $\mathrm{n}=20)$. At the end of day 90 , there were $11.80 \pm 2.59(\mathrm{mean} \pm$

161 SE) female and $4.75 \pm 1.06$ male ergatoids differentiated when they were removed daily,

162 compared to only $2.60 \pm 0.34$ female and $1.05 \pm 0.05$ male ergatoids if they were not removed.

163 In addition, there was a significantly higher overall mortality in "non-removal" than that in

164 "removal" treatment (Figure $\mathrm{S} 1 ; \mathrm{x}^{2}=30.36, \mathrm{df}=1, P<0.001 ;$ GLMM, Poisson family; $\mathrm{n}=20$ ).

165 In "non-removal" groups, we frequently observed injured ergatoids partially consumed by

166 workers, along with other intact ergatoids. Between the two treatments, the mortality difference

167 (8.6 individuals at day 60 and 10.2 at day 90) closely matched the difference in the number of

168 ergatoids that differentiated and that survived (6.2 at day 60 and 12.9 at day 90), suggesting

169 cannibalism of ergatoids in "non-removal" treatment is primarily responsible for the difference

170 in mortality.

171 (b) Ergatoids and workers cooperate in elimination of excessive ergatoids

172 A total of seven events were captured with full behavioral process, which started with one

173 ergatoid attacking another ergatoid and ended with the injured individual being cannibalized by

174 workers (Figure 2, Table S1, Movies S1-S4). In this behavior, the attacker antennated the victim

175 first, and used mouthparts to hold the abdomen or thorax of the victim before biting. The bite

176 always caused the victim to leak hemolymph and quickly flee. Right after the attack, the attacker

177 displayed alarm behavior by vigorously vibrating the body toward multiple directions;

178 interestingly, the ergatoids who did not participate in the aggression (i.e., bystanders) also

179 performed alarm behavior after the attack, while the victim rarely engaged in vibration (Figure

180 3a). Workers, on average, displayed little vibration (Figure 3a). With the alarm of ergatoids, 
181 workers rapidly began to surround the injured victim, biting and consuming it while it was still

182 alive, and the cannibalism reached a peak 30 minutes after the attack (Figure $3 b$ ). As the

183 cannibalism began to decline due to little of the remaining body to consume, the ergatoid

184 attacker and bystanders began to decline in the frequency of alarm (45 to 60 minutes after the

185 attack) (Figure 3a). Soldiers did not participate in either alarm behavior or cannibalism (Figure

$1863 a, 3 b)$.

187 (c) Ergatoid elimination is age-dependent

188 The majority of the aggressive interactions involved an ergatoid attacking the same-sex ergatoid

189 (15 out of 19), while the others involved either a male ergatoid attacking a female (1 out 19), or a

190 group of workers attacking and consuming an ergatoid ( 1 and 2 cases in female and male

191 treatments, respectively). In the same-sex aggressive interactions, the attacker was always older

192 than the victim in both female and male treatments (Figure 4; female: $Z=-2.3664, P<0.01, \mathrm{n}=$

1937 ; male: $Z=-2.5205, P<0.01, \mathrm{n}=8$; Wilcoxon signed-rank test, one-tailed). The median age

194 differences between the pair of attacker and victim were 5 and 2 days for females and males,

195 respectively.

197 4. Discussion

198 (a) Cooperative effort and justification of "policing behavior"

199 Overall, this study reveals a behavioral mechanism regulating reproductive division of labor

200 during reproductive succession in termites. Unlike butting behavior that is an indicator of

201 reproductive dominance reported in a drywood termite Cryptotermes secundus and a dampwood

202 termite Zootermopsis nevadensis [37, 38], this behavior directly acts to eliminate reproductive

203 individuals, thus fulfilling the definition of policing [10]. 
205 reproductives in concert with workers. This is comparable to the sting smearing behavior in a

206 queenless ant, Dinoponera quadriceps, a textbook example of policing behavior [39]. In this ant,

207 the alpha female chemically marks a low-ranking challenger using stinger, causing workers to

208 immobilize the marked individual [40]. Such a cooperative effort allows the alpha to inflict

209 punishment indirectly and maintain her dominant status without fighting. Similarly, in $R$. flavipes,

210 the ergatoid attacker does not kill its rival directly; rather, it induces hemolymph exposure of the

211 victim by biting, and proceeds with an alarm behavior. Workers eventually eliminate the injured

212 individual. The workers are likely recruited by the vibrational signals, and the cannibalistic

213 behavior is potentially caused by the chemical cues in the hemolymph, which remains to be

214 investigated.

\section{5 (b) Caste fate conflict}

216 In the absence of reproductives and their inhibitory pheromones, the excess ergatoid production

217 in $R$. flavipes is an expression of caste fate conflict, which also occurs in social Hymenoptera.

218 For example, in the Melipona stingless bees, caste is self-determined, and immature females

219 selfishly develop into queens to maximize direct reproduction [41]. Such excess queen

220 production causes depletion of workforce and poses a cost to the colony, leading to a situation

221 known as "tragedy of the commons" [42]. The policing behavior in $R$. flavipes provides an

222 effective solution that prevents unsustainable reproduction upon the loss of former reproductives,

223 and supports colony efficiency. Uncontrolled reproduction causes increased resource demand by

224 the reproductive individuals and their brood, and a balanced ratio of reproductives and workers is

225 often optimal to the colony. For example, in a parthenogenic ant Platythyrea punctate, worker to

226 brood ratio is limited, and colonies are incapable of rearing brood produced by additional 
227 reproductives [23]. Similarly, an optimal allocation to reproduction is required in the Japanese

228 subterranean termite $R$. speratus, and increased number of queens does not lead to additional

229 reproductive output [43].

230 In social insects, policing often inhibits reproduction of the focal individual without

231 killing it. In Hymenoptera, policing behavior often enforces workers to stop reproducing and

232 cooperate in brood care. In subterranean termites, however, worker-reproductive differentiation

233 is an irreversible process achieved through at least one molt [25]. Ergatoid reproductives are a

234 non-foraging caste that depends on workers to provide food [44], and the presence of excess

235 ergatoids and the subsequent brood are costly for the colony. Elimination of additional ergatoids

236 avoids future colony investment; cannibalism, in addition, allows the colony to recycle nutrients

237 from the policed individuals and partially rescue the cost that has already occurred upon their

238 differentiation.

\section{9 (c) Age-dependent elimination}

240 The age of ergatoids plays an important role in the policing behavior of $R$. flavipes. The result is

241 consistent with a dampwood termite Porotermes adamsoni, in which neotenic reproductives that

242 develop earlier have higher survivorship than that differentiate later [45]. Age is also positively

243 correlated with dominance rank in the naked mole-rat Heterocephalus glaber [46], in which

244 younger individuals receive more aggression than older ones [47]. In termites, older ergatoids

245 have the first chance to utilize resources from the colony, such as food provided by workers and

246 mating opportunities with existing reproductives. These factors may contribute to the maturity of

247 ergatoids in terms of gonad development [48], body weight, and mandible sclerotization, thus

248 allowing them to outcompete the younger ones. In C. secundus, the surviving neotenics

249 performed increased interactions with workers through proctodeal trophallaxis after their 
250 differentiation, while the ones eventually eliminated did not [30]. This behavior is possibly

251 associated with age, but it is yet to be tested if neotenics increase trophallaxis as they become

252 older.

253 The elimination of younger ergatoids in termites is also similar to the selective

254 elimination of small queens in a stingless bee Schwarziana quadripunctata, where large fecund

255 queens are favored and dwarf queens tend to be killed by workers [49]. With a policing behavior

256 that strongly acts against small queens, small females should be less tempted to develop into

257 queens, a situation indicated by a theoretical study based on inclusive fitness theory [49]. In $R$.

258 flavipes, while a few ergatoids are formed and eliminated, the majority of workers do not molt

259 into ergatoids. This suggests that the same theory may apply to termites: in the presence of older

260 ergatoid, rather than developing into reproductives and being killed, workers can gain indirect

261 fitness benefits by not differentiating.

\section{2 (d) Reproductive competition}

263 The aggressive interaction between ergatoids in termites reflects competition among colony

264 members in inheriting the breeding position after the death of primary reproductives. This form

265 of cooperative policing might be common in termite species where workers or nymphs retain

266 reproductive potential and compete for breeding positions. Indeed, a similar behavior has been

267 observed in a drywood termite, Kalotermes flavicollis, where neotenic reproductives attack each

268 other and injured individuals are cannibalized by workers and nymphs [34]. In addition,

269 reproductive competition also occurs upon fusion of neighboring conspecific colonies. In $Z$.

270 nevadensis, reproductives of encountering colonies engage in agonistic behavior, leading to a

271 reduction in their numbers [50]. Moreover, reproductive conflict among unrelated queens

272 happens in species where colonies are founded by pleometrosis. In a fungus-growing termite, 
273 Macrotermes michaelseni, the mutilation of queen antennae indicates aggression between

274 primary reproductives that are co-founders, and this behavior may influence queen number [51].

275 These findings suggest that aggressive interaction between reproductives is widespread in

276 termites under diverse social contexts. Aggression represents a conserved component of policing

277 behavior, which, at colony level, regulates reproductive division of labor and serve a collective

278 interest.

279 (e) Future directions

280 Several open questions remain to be addressed in regard to the pheromonal mechanisms

281 underlying policing behavior, including the dynamic change of reproductive pheromones with

282 age, and the chemical cues inducing cannibalism of ergatoids by workers. Importantly, policing

283 behavior, in a broad sense, may be more widespread in termites than previously considered. In

284 addition to a number of convergent traits in social Hymenoptera and Blattodea, such as suicidal

285 colony defense [52], collective foraging using trail pheromones [53], and undertaking behavior

286 [54], policing behavior represents another important behavior that independently evolved in both

287 eusocial groups. Comparative studies on proximate and ultimate aspects of policing behavior

288 among social insect taxa will provide important insights into the evolution of eusociality in

289 insects. 
290 Supplementary material. Supplementary material includes 1 table, 1 figure, and 4 movies.

291 Data accessibility. Raw data can be accessed as supplementary material.

292 Authors' contributions. Q.S., J.D.H. contributed equally to this study. Q.S., J.D.H., K.F.H. and

293 X.Z. designed the study. Q.S. and J.D.H. performed the experiments. Q.S., J.D.H and A.M

294 analyzed the data. Q.S., J.D.H., K.F.H. and X.Z. wrote the manuscript. All authors read and

295 approved the final manuscript.

296 Competing interests. The authors declare no competing interests.

297 Acknowledgments. We thank members of Zhou laboratory for discussion and comments on the

298 study. This work was supported by William L. and Ruth D. Nutting Student Research Grant from

299 the International Union for the Study of Social Insects (North American Section) to Q.S., and a

300 Hatch fund (Accession Number: 1004654; Project Number: KY008071) from the USDA

301 National Institute of Food and Agriculture to X.Z. 


\section{References}

303

304 1. Robinson, G.E. (1992). Regulation of division of labor in insect societies. Annu. Rev.

$305 \quad$ Entomol. 37, 637-665.

306 2. Ratnieks, F.L., Foster, K.R., and Wenseleers, T. (2006). Conflict resolution in insect

307 societies. Annu. Rev. Entomol. 51, 581-608.

308 3. Hart, A.G., and Monnin, T. (2006). Conflict over the timing of breeder replacement in

309 vertebrate and invertebrate societies. Insectes Soc. 53, 375-389.

310 4. Korb, J. (2018). Chemical fertility signaling in termites: idiosyncrasies and

311 commonalities in comparison with ants. J. Chem. Ecol. 44, 818-826.

312 5. Conte, Y.L., and Hefetz, A. (2008). Primer pheromones in social Hymenoptera. Annu.

313 Rev. Entomol. 53, 523-542.

314 6. Matsuura, K., Himuro, C., Yokoi, T., Yamamoto, Y., Vargo, E.L., and Keller, L. (2010).

315 Identification of a pheromone regulating caste differentiation in termites. Proc. Natl.

$316 \quad$ Acad. Sci. U. S. A. 107, 12963-12968.

317 7. Holman, L., Jørgensen, C.G., Nielsen, J., and d'Ettorre, P. (2010). Identification of an ant 318 queen pheromone regulating worker sterility. Proc. Royal Soc. B 277, 3793-3800.

319 8. Ratnieks, F.L.W. (1988). Reproductive harmony via mutual policing by workers in 320 eusocial Hymenoptera. Am. Nat. 132, 217-236.

321 9. Oster, G.F., and Wilson, E.O. (1978). Caste and ecology in the social insects (Princeton $322 \quad$ University Press).

323 10. Monnin, T., and Ratnieks, F.L. (2001). Policing in queenless ponerine ants. Behav. Ecol. $324 \quad$ Sociobiol. 50, 97-108. 
325 11. Ratnieks, F.L.W., and Visscher, P.K. (1989). Worker policing in the honeybee. Nature $326 \quad 342,796-797$.

327 12. Wenseleers, T., Tofilski, A., and Ratnieks, F.L.W. (2005). Queen and worker policing in 328 the tree wasp Dolichovespula sylvestris. Behav. Ecol. Sociobiol. 58, 80-86.

329 13. Foster, K.R., and Ratnieks, F.L.W. (2001). Convergent evolution of worker policing by 330 egg eating in the honeybee and common wasp. Proc. Royal Soc. B 268, 169-174.

331 14. Bourke, A.F.G. (1991). Queen behaviour, reproduction and egg cannibalism in multiple332 queen colonies of the ant Leptothorax acervorum. Anim. Behav. 42, 295-310.

333 15. Medeiros, F.N.S., Lopes, L.E., Moutinho, P.R.S., Oliveira, P.S., and Hölldobler, B. 334 (1992). Functional polygyny, agonistic interactions and reproductive dominance in the 335 Neotropical ant Odontomachus chelifer (Hymenoptera, Formicidae, Ponerinae). Ethology $33691,134-146$.

337 16. Adams, E.S., and Balas, M.T. (1999). Worker discrimination among queens in newly 338 founded colonies of the fire ant Solenopsis invicta. Behav. Ecol. Sociobiol. 45, 330-338.

339 17. Loope, K. (2015). Queen killing is linked to high worker-worker relatedness in a social $340 \quad$ wasp. Curr. Biol. 25, 2976-2979.

341 18. Monnin, T., and Peeters, C. (1997). Cannibalism of subordinates' eggs in the 342 monogynous queenless ant Dinoponera quadriceps. Naturwissenschaften 84, 499-502.

343 19. Misof, B., Liu, S., Meusemann, K., Peters, R.S., Donath, A., Mayer, C., Frandsen, P.B., 344 Ware, J., Flouri, T., Beutel, R.G., et al. (2014). Phylogenomics resolves the timing and 345 pattern of insect evolution. Science 346, 763-767. 
346 20. Tom Wenseleers, and Francis L. W. Ratnieks (2006). Comparative analysis of worker

347 reproduction and policing in eusocial Hymenoptera supports relatedness theory. Am. Nat.

$348 \quad 168$, E163-E179.

349 21. Walter, B., Brunner, E., and Heinze, J. (2011). Policing effectiveness depends on

350 relatedness and group size. Am. Nat. 177, 368-376.

351 22. Ratnieks, F.L.W., and Reeve, H.K. (1992). Conflict in single-queen hymenopteran

352 societies: the structure of conflict and processes that reduce conflict in advanced eusocial

353 species. J. Theor. Biol. 158, 33-65.

354 23. Hartmann, A., Wantia, J., Torres, J.A., and Heinze, J. (2003). Worker policing without

355 genetic conflicts in a clonal ant. Proc. Natl. Acad. Sci. U. S. A. 100, 12836-12840.

356 24. Teseo, S., Kronauer, D.J.C., Jaisson, P., and Châline, N. (2013). Enforcement of

357 reproductive synchrony via policing in a clonal ant. Curr. Biol. 23, 328-332.

358 25. Korb, J., and Hartfelder, K. (2008). Life history and development - a framework for

359 understanding developmental plasticity in lower termites. Biol. Rev. 83, 295-313.

360 26. Myles, T.G. (1999). Review of secondary reproduction in termites (Insecta: Isoptera)

361 with comments on its role in termite ecology and social evolution. Sociobiology 33, 1-43.

362 27. Bartz, S.H. (1979). Evolution of eusociality in termites. Proc. Natl. Acad. Sci. U. S. A. 76, $363 \quad 5764-5768$.

364 28. Matsuura, K. (2012). Multifunctional queen pheromone and maintenance of reproductive 365 harmony in termite colonies. J. Chem. Ecol. 38, 746-754.

366 29. Sun, Q., Haynes, K.F., Hampton, J.D., and Zhou, X. (2017). Sex-specific inhibition and 367 stimulation of worker-reproductive transition in a termite. Sci. Nat. 104, 79. 
368 30. Hoffmann, K., and Korb, J. (2011). Is there conflict over direct reproduction in lower

369 termite colonies? Anim. Behav. 81, 265-274.

370 31. Lenz, M. (1985). Is inter-and intraspecific variability of lower termite neotenic numbers

371 due to adaptive thresholds for neotenic elimination? - Considerations from studies on

$372 \quad$ Porotermes adamsoni (Froggatt)(Isoptera: Termopsidae). In Caste differentiation in

373 social insects, Volume 3, J.A.L. Watson, B.M. Okot-Kotber and C. Noirot, eds. (Oxford:

$374 \quad$ Pergamon Press), p. 125.

375 32. Lenz, M., McMahan, E.A., and Williams, E.R. (1982). Neotenic production in

376 Cryptotermes brevis (Walker): Influence of geographical origin, group composition, and

377 maintenance conditions (Isoptera: Kalotermitidae). Insectes Soc. 29, 148-163.

378 33. Lüscher, M. (1952). Die produktion und elimination von ersatzgeschlechtstieren bei der 379 termite Kalotermes flavicollis Fabr. J. Comp. Physiol. A 34, 123-141.

380 34. Ruppli, E. (1969). Die Elimination Überzähliger Ersatzgeschlechtstiere bei der Termite $381 \quad$ Kalotermes Flavicollis (Fabr.). Insectes Soc. 16, 235-248.

382 35. Costa-Leonardo, A.M., Arab, A., and Casarin, F.E. (2004). Neotenic formation in

383 laboratory colonies of the termite Coptotermes gestroi after orphaning. J. Insect Sci. 4, 10.

384 36. Miyata, H., Furuichi, H., and Kitade, O. (2004). Patterns of neotenic differentiation in a 385 subterranean termite, Reticulitermes speratus (Isoptera: Rhinotermitidae). Entomol. Sci. 7, $386 \quad 309-314$

387 37. Korb, J., Weil, T., Hoffmann, K., Foster, K.R., and Rehli, M. (2009). A gene necessary

388 for reproductive suppression in termites. Science $324,758-758$. 
38. Penick, C.A., Trobaugh, B., Brent, C.S., and Liebig, J. (2013). Head-butting as an early indicator of reproductive disinhibition in the termite Zootermopsis nevadensis. J. Insect Behav. 26, 23-34.

392 39. Rubenstein, D.R., and Alcock, J. (2019). Animal Behavior, (Sinauer Associates).

393 40. Monnin, T., Ratnieks, F.L.W., Jones, G.R., and Beard, R. (2002). Pretender punishment

41. Wenseleers, T., Ratnieks, F.L., and Billen, J. (2003). Caste fate conflict in swarmfounding social Hymenoptera: an inclusive fitness analysis. J. Evol. Biol. 16, 647-658.

397 42. Wenseleers, T., and Ratnieks, F.L. (2004). Tragedy of the commons in Melipona bees. Proc. Royal Soc. B 271, S310-S312.

43. Yamamoto, Y., and Matsuura, K. (2011). Queen pheromone regulates egg production in a termite. Biol. Lett. 7, 727-729.

401 44. Eggleton, P. (2011). An introduction to termites: biology, taxonomy and functional morphology. In Biology of Termites: a Modern Synthesis, D.E. Bignell, Y. Roisin and N.

404 45. Mensa-Bonsu, A. (1976). The production and elimination of supplementary reproductives in Porotermes adamsoni (Froggatt) (Isoptera, Hodotermitidae). Insectes Soc. 23, 133-153.

406 46. Clarke, F.M., and Faulkes, C.G. (1997). Dominance and queen succession in captive 407 colonies of the eusocial naked mole-rat, Heterocephalus glaber. Proc. Royal Soc. B 264, 993-1000.

409 47. O'Riain, J. (1996). Pup ontogeny and factors influencing behavioural and morphological $410 \quad$ variation in naked mole-rats, Heterocephalus glaber (Rodentia, Bathyergidae). In 411 Zoology, Volume Ph.D. (University of Cape Town). 
412 48. Brent, C.S., and Traniello, J.F.A. (2001). Social influence of larvae on ovarian maturation

413 in primary and secondary reproductives of the dampwood termite Zootermopsis

$414 \quad$ angusticollis. Physiol. Entomol. 26, 78-85.

415 49. Wenseleers, T., Hart, A.G., and Ratnieks, F.L. (2004). When resistance is useless:

416 policing and the evolution of reproductive acquiescence in insect societies. Am. Nat. 164,

$417 \quad$ E154-E167.

418 50. Thorne, B.L., Breisch, N.L., and Muscedere, M.L. (2003). Evolution of eusociality and

419 the soldier caste in termites: Influence of intraspecific competition and accelerated

420 inheritance. Proc. Natl. Acad. Sci. U. S. A. 100, 12808-12813.

421 51. Brandl, R., Hacker, M., Bagine, R., and Kaib, M. (2001). Geographic variation of

422 polygyny in the termite Macrotermes michaelseni (Sjöstedt). Insectes Soc. 48, 134-137.

423 52. Shorter, J., and Rueppell, O. (2012). A review on self-destructive defense behaviors in 424 social insects. Insectes Soc. 59, 1-10.

425 53. Czaczkes, T.J., Grüter, C., and Ratnieks, F.L. (2015). Trail pheromones: an integrative 426 view of their role in social insect colony organization. Annu. Rev. Entomol. 60, 581-599.

427 54. Sun, Q., Haynes, K.F., and Zhou, X. (2018). Managing the risks and rewards of death in 428 eusocial insects. Philos. Trans. R. Soc. B 373, 20170258. 

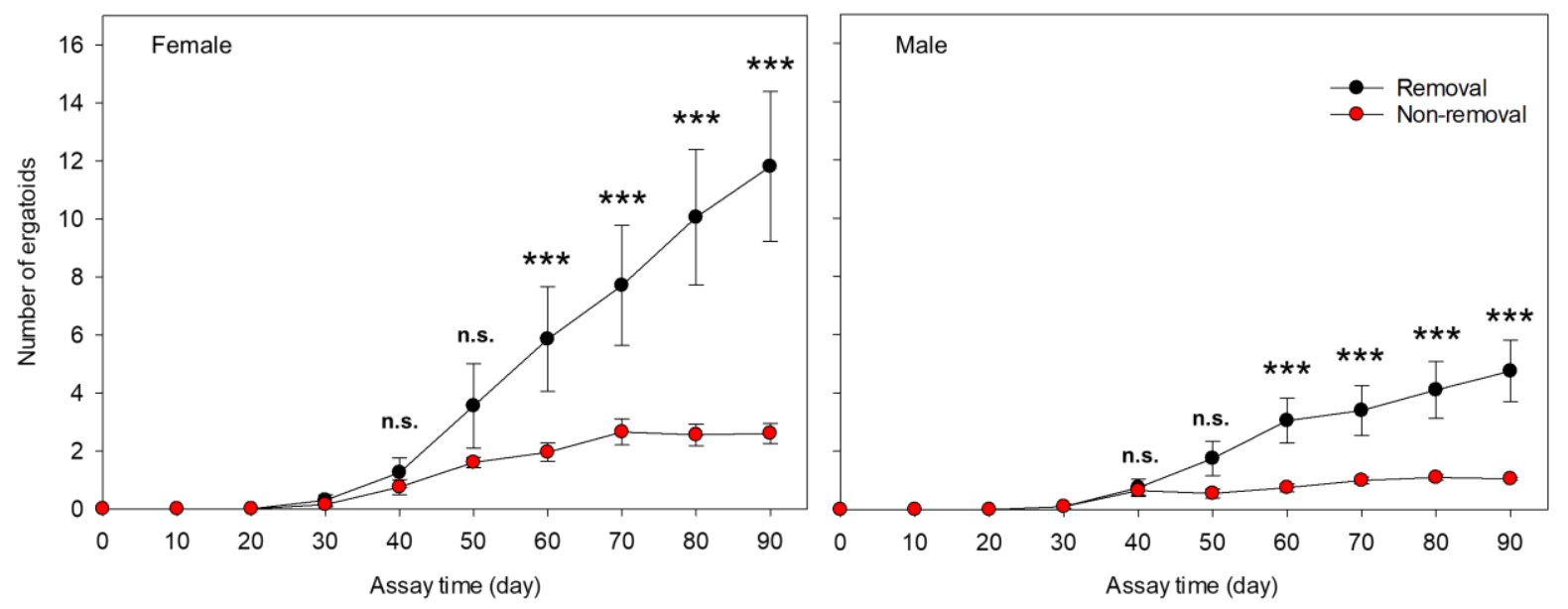

Figure 1. Restriction of ergatoid numbers in orphaning assay. Female and male ergatoids that

433 formed from groups of 100 workers were documented for 90 days post establishment of

434 experiment. Cumulative number of differentiated ergatoids (removal treatment) and surviving

435 number of ergatoids (non-removal treatment) are presented (mean \pm SE) and compared within

436 the same observation day. n.s., not significant; ***, $P<0.001$; GLMM, Poisson family; $\mathrm{n}=20$

437 per treatment per observation day. 

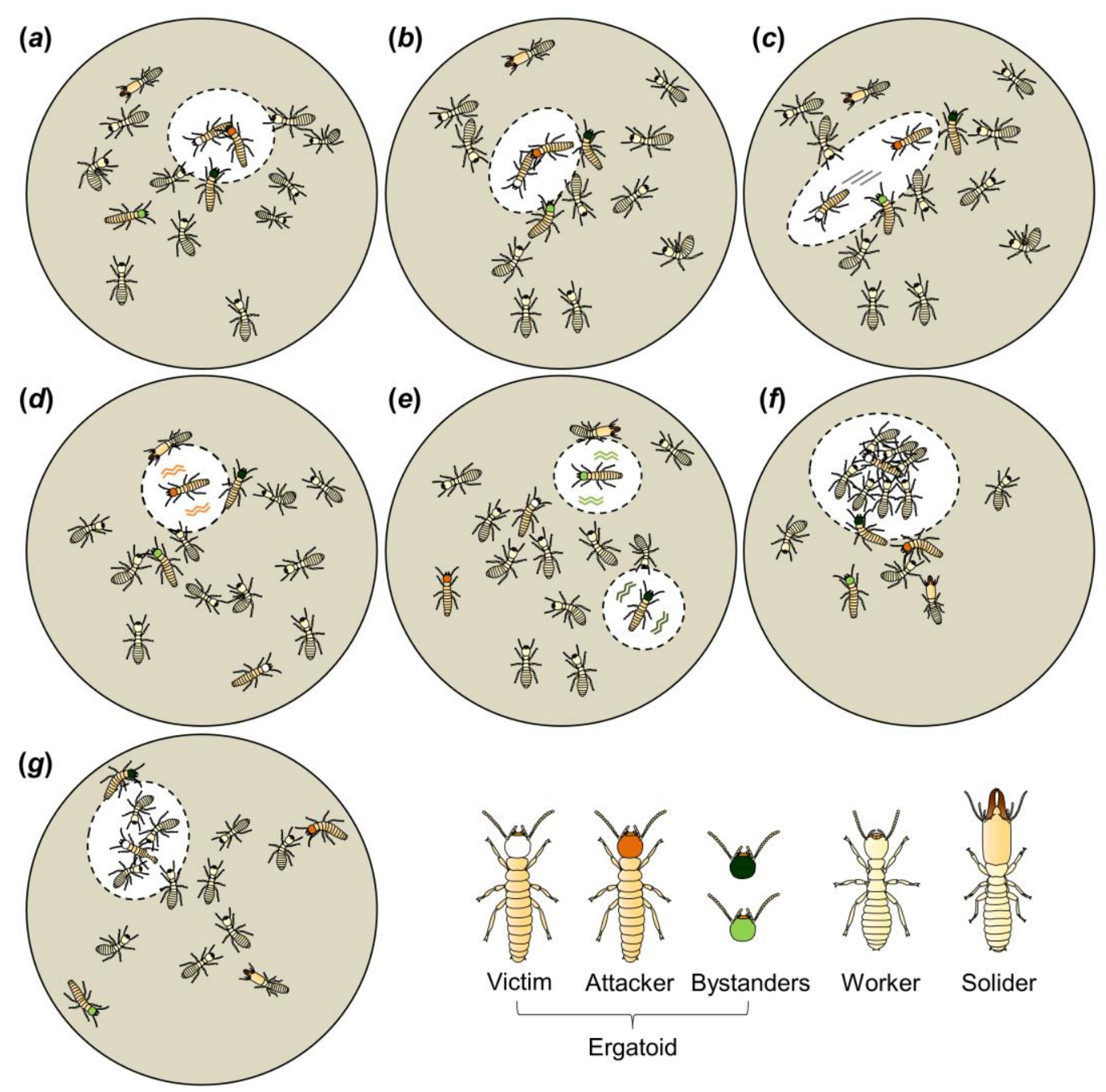

439 Figure 2. Behavioral process of cooperative policing. (a) An ergatoid attacker holds the victim

440 using mouthparts (Time $=-10 \mathrm{sec}$ ). (b) The attacker performs a major attack by biting the victim

441 on its abdomen (Time $=0)$. (c) The major attack causes the victim to quickly flee (Time $=0)$. (d)

442 The attacker displays alarm behavior by vigorously vibrating its body toward multiple directions

443 (Time $=1 \mathrm{~min}$ ). (e) Bystanders also display alarm behavior in the same manner $($ Time $=5 \mathrm{~min})$.

444 (f) Workers then surround and nibble the victim (Time $=30 \mathrm{~min}$ ). (g) Victim is partially

445 cannibalized (Time $=2$ hour). Attacker: ergatoid who performed the first major attack. Victim:

446 ergatoid who received the attack and was later cannibalized. Bystander: other ergatoids. 
(a)

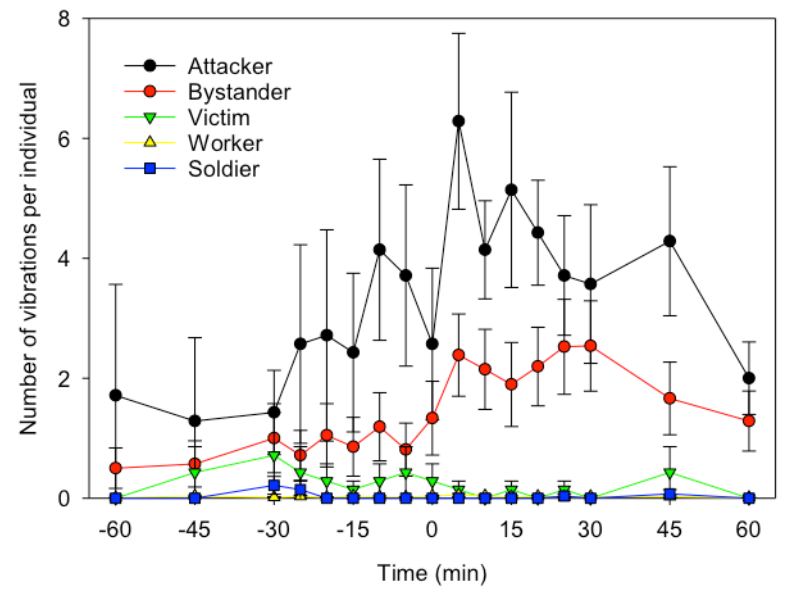

(b)

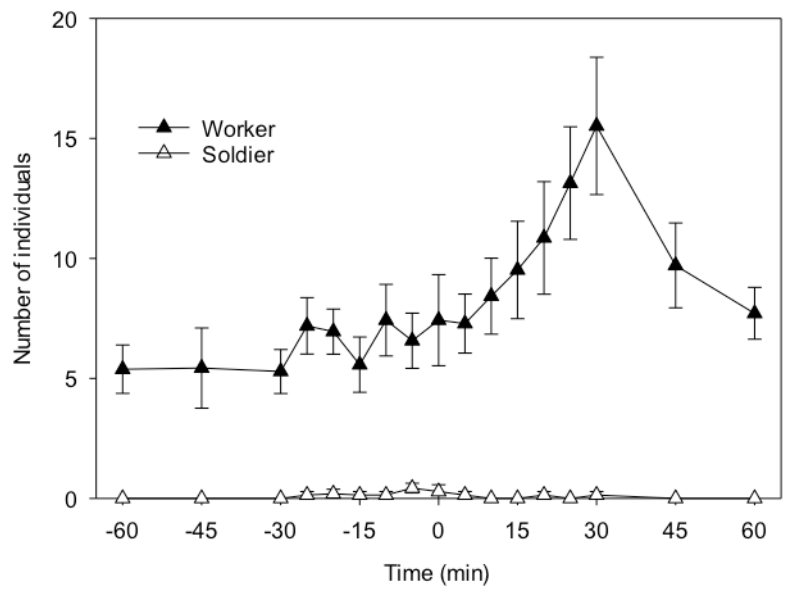

448 Figure 3. Participation of different castes in policing behavior. (a) Figure shows the number of

449 vibrations per minute performed by each individual (mean $\pm \mathrm{SE}, \mathrm{n}=7$ ). Time " 0 " was the time

450 of the first major attack. A major attack was recognized when an ergatoid visibly injured another

451 ergatoid. A one-minute sample (30 seconds before and after) was analyzed for each time point.

452 (b) The number of individuals surrounding the victim before and after the attack (mean $\pm \mathrm{SE}, \mathrm{n}=$

453 7). The increased density of workers reflects cannibalism. 

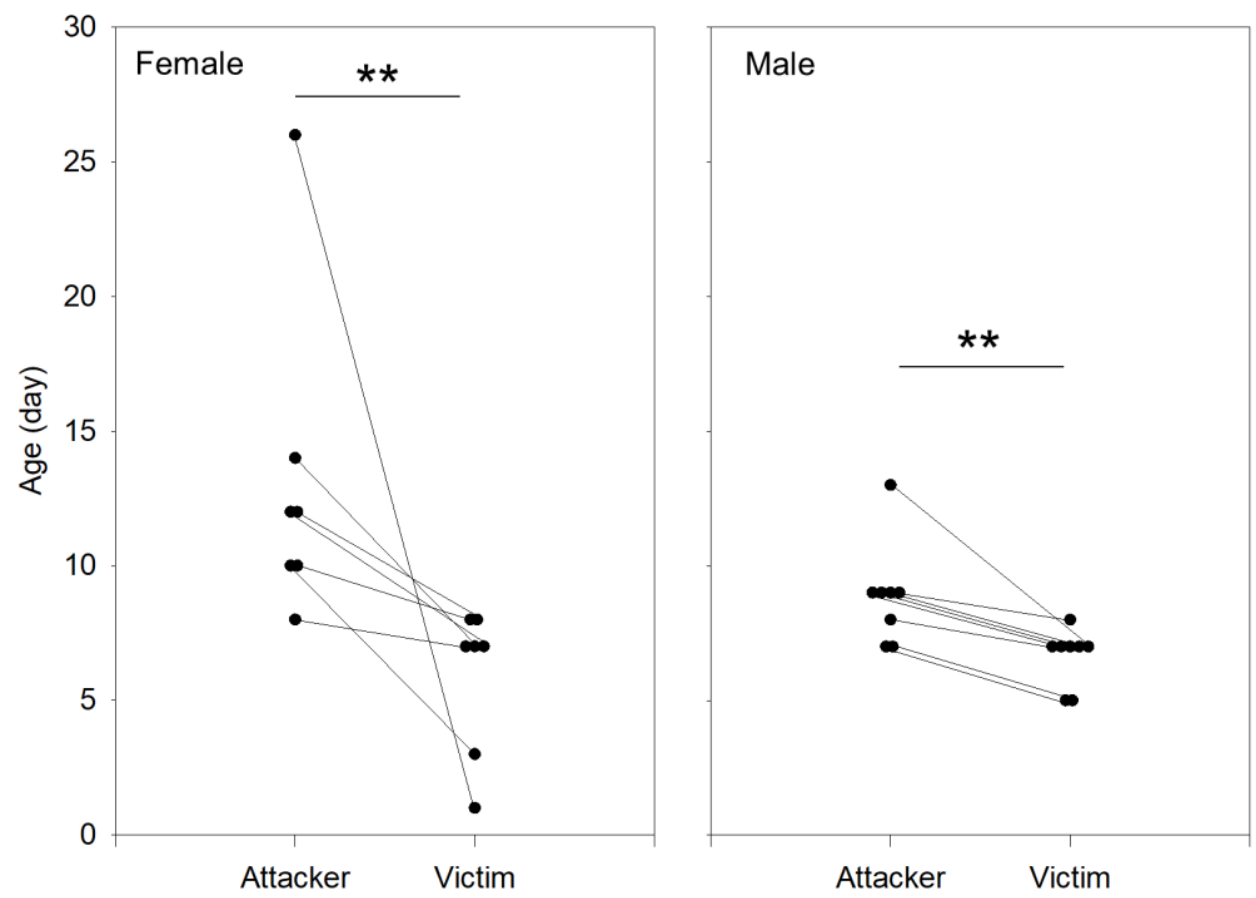

455 Figure 4. Age of interacting ergatoids in policing behavior. Each dot represents an individual

456 attacker or victim, and lines connect the attacker to the corresponding victim. The negative slope

457 of the lines in both graphs shows that an older ergatoid attacked a younger ergatoid in every

458 replication, and the age differences are significant (female: $\mathrm{Z}=-2.3664, P<0.01, \mathrm{n}=7$; male: $\mathrm{Z}$

$459=-2.5205, \mathrm{P}<0.01, \mathrm{n}=8$; Wilcoxon signed-rank test, one-tailed; $* *, P<0.01)$. 